\title{
SWE and SMI ultrasound techniques for monitoring needling treatment of ankylosing spondylitis: study protocol for a single-blinded randomized controlled trial
}

\author{
Mengyu Wang ${ }^{1 \dagger}$, Wen Fu ${ }^{2 \dagger}$, Lingcui Meng ${ }^{3}$, Jia Liư ${ }^{3}$, Lihua Wu ${ }^{4}$, Yingjun Peng ${ }^{1}$ and Ziping $\mathrm{Li}^{3 *}$
}

\begin{abstract}
Background: Ankylosing spondylitis (AS) is a high-incidence disease in young men that interferes with patients' physical and mental wellbeing and overall quality of life (QoL). It is often accompanied by arthralgia, stiffness, and limited lumbar flexibility. Acupuncture is safe and effective for reducing the symptoms of AS, but the underlying mechanisms by which it does so are not fully understood. Therefore, to objectively assess acupuncture efficacy, which is critical for patients making informed decisions about appropriate treatments, we will use shear-wave elastography (SWE) and superb microvascular imaging (SMI) ultrasound techniques to evaluate elasticity of lumbar paraspinal muscles and blood flow to the sacroiliac joint (SIJ) in AS.
\end{abstract}

Methods: We will recruit a total of 60 participants diagnosed with AS and 30 healthy subjects. Participants will be randomly allocated 1:1 to either an acupuncture group or a sham control acupuncture group. Primary-outcome measures will be musculoskeletal ultrasound, Ankylosing Spondylitis Quality of Life Scale (ASQoL), Bath Ankylosing Spondylitis Metrology Index (BASMI), and the Visual Analogue Scale (VAS) for pain. Secondary outcome measures will be the Bath Ankylosing Spondylitis Disease Activity Index (BASDAl), Bath Ankylosing Spondylitis Function Index (BASFI), and Fatigue Scale-14 (FS-14). We will monitor the effect of acupuncture or sham acupuncture on blood flow and SIJ inflammation using SMI, lumbar-muscle stiffness using SWE and the lumbar paraspinal-muscle crosssectional area (CSA) using a two-dimensional (2D) grayscale imaging. QoL, physical function, and fatigue will be assessed using an evaluation scale or questionnaire developed for this study, with outcomes measured by the ASQoL, BASMI, BASDAI, BASFI, and FS-14. Healthy subjects will not receive acupuncture but undergo only musculoskeletal ultrasound at baseline. Acupuncture and sham control acupuncture interventions will be conducted for 30 min, 2-3 times/week for 12 weeks. Musculoskeletal ultrasound will be conducted at baseline and post-intervention, while other outcomes will be measured at baseline, 6 weeks, and post-intervention. The statistician, outcome assessor, and participants will be blinded to treatment allocation.

\footnotetext{
* Correspondence: Izip 008@163.com

${ }^{\dagger}$ Mengyu Wang and Wen Fu contributed equally to this work. Mengyu Wang and Wen Fu are joint first authors.

${ }^{3}$ The Second Affiliated Hospital of Guangzhou University of Chinese Medicine, 111 Dade Rd, Guangzhou 510120, Guangdong Province, China Full list of author information is available at the end of the article
}

C C The Author(s). 2021 Open Access This article is licensed under a Creative Commons Attribution 4.0 International License, which permits use, sharing, adaptation, distribution and reproduction in any medium or format, as long as you give appropriate credit to the original author(s) and the source, provide a link to the Creative Commons licence, and indicate if changes were made. The images or other third party material in this article are included in the article's Creative Commons licence, unless indicated otherwise in a credit line to the material. If material is not included in the article's Creative Commons licence and your intended use is not permitted by statutory regulation or exceeds the permitted use, you will need to obtain permission directly from the copyright holder. To view a copy of this licence, visit http://creativecommons.org/licenses/by/4.0/ The Creative Commons Public Domain Dedication waiver (http://creativecommons.org/publicdomain/zero/1.0/) applies to the data made available in this article, unless otherwise stated in a credit line to the data. 
Discussion: The results of this single-blinded, randomized trial with sham controls could help demonstrate the efficacy of acupuncture and clarify whether musculoskeletal ultrasound could be used to evaluate AS.

Trial registration: ClinicalTrials.gov ChiCTR2000031476. Registered 3 April 2020.

Keywords: Acupuncture, Ankylosing spondylitis, Musculoskeletal ultrasound, Physical dysfunction, Randomized controlled trial

\section{Background}

Ankylosing spondylitis (AS) is a systemic disease characterized by chronic inflammation of the axial joint, involving the sacroiliac joint (SIJ), with primary clinical symptoms of arthralgia, stiffness, and limited flexibility [1]. Over the past 15years, the total prevalence of AS in the mainland China has been $0.29 \%$, ranging from $0.42 \%$ in males to $0.15 \%$ in females [2]. The primary pathology includes inflammation of the bony attachments of tendons, ligaments, or joint capsules [3]. Physical dysfunction in AS can potentiate serious health conditions and lead to fatigue, depression, anxiety, and decreased quality of life (QoL) [4, 5]. The disease imposes substantial physical and social burdens on patients and can interfere with work and schooling [6, 7]. The goals of treatment are to alleviate symptoms, improve functioning, decrease disease complications, and forestall skeletal damage as much as possible [8]. The use of non-steroidal anti-inflammatory drugs (NSAIDs) and very expensive biologics is recommended for treatment [9]. However, due to the significant side effects [10], development of therapeutic resistance to drug treatment [11] and high drug costs, such use places a huge burden on patients. Thus, nonpharmacological intervention has become one of the most important options for AS [12]. Alternative therapies play an important role in treating this disease; for example, a combination of the Traditional Chinese Medicine (TCM) with, especially, acupuncture can achieve better effect.

Acupuncture is a safe alternative therapy with minimal side effects that has shown benefits in alleviating symptoms, reducing complications, and accelerating recovery in AS [13], and it has been shown to improve joint functional flexibility when used in the management of pain and rheumatic diseases [14-17]. Previous systematic studies support that acupuncture could be an option for treating AS $[18,19]$.

The 2019 guidelines of the American College of Rheumatology (ACR) [8] state that magnetic resonance imaging (MRI) is not suitable for detecting subclinical inflammation in patients with stable disease and recommend against patients obtaining spine radiographs at scheduled intervals to monitor progression, as the practice entails radiation exposure and will not lead to alteration of treatment in most cases. Therefore, it is particularly important to find a method that is safe and can be used at short intervals to detect subclinical inflammation in a timely manner. Ultrasound has become part of the fundamental Outcome Measures in Rheumatology (OMERACT) methodology validation by repeatedly exercises across various domains, including inflammatory burden and structural damage [20, 21]. Musculoskeletal ultrasound is a reliable evaluation method that directly visualizes characteristics of rheumatic conditions such as synovitis, tenosynovitis, bursitis, enthesitis, crystal depositions, bone erosions, or osteophytes/enthesophytes. It is more sensitive than X-ray or MRI in physical tendons, ligaments, or joint capsules [22, 23]. Early detection of subclinical lesions can help decision makers improve the quality of their daily clinical practice in rheumatic diseases.

Although musculoskeletal ultrasound is less sensitive than MRI and X-ray in early detection of synovitis and tenosynovitis [24], it is suitable for short-term evaluation of stable rheumatic diseases, offering highly accessible, low-cost, real-time imaging without radiation $[25,26]$. The OMERACT Ultrasound Working Group has engaged in the validation of ultrasound as an outcome measurement instrument (OMI) by defining ultrasound manifestations of spondyloarthritis (SpA) [27].

This high-quality, randomized controlled trial (RCT) was designed via a pragmatic trial approach to objectively assess the efficacy of acupuncture using musculoskeletal ultrasound and a sham acupuncture group.

\section{Objectives}

Our research hypotheses are as follows: (1) musculoskeletal ultrasound will be used as a short-term effectiveexamination method and objective auxiliary-examination method for AS. (2) Acupuncture will reduce subjective pain rating, improve joint functional flexibility, and the effect of pain on ASQoL.

\section{Methods/design \\ Study setting}

The study will follow the principles of the Consolidated Standards of Reporting Trials (CONSORT) for a twoarm randomized, superiority, parallel control clinical trial, as well as the Standards for Reporting Interventions in Clinical Trials of Acupuncture (STRICTA) statement for acupuncture [28, 29]. This will be a single-blinded 
RCT with a sample size based on published evidence in comparative studies. Sixty AS patients will be randomly established at a 1:1 ratio, including the acupuncture group and sham control acupuncture group. At the same time, thirty healthy volunteers will be recruited as blank control group. The sham control acupuncture group is set for placebo control to evaluate the clinical efficacy of acupuncture. AS patients blinded to study conditions. The study will be conducted at the Guangdong Provincial Hospital of Chinese Medicine (GPHC M), Department of Acupuncture, Guangdong, China, following the Standard Protocol Items: Recommendations for Interventional Trials (SPIRIT). For the participant timeline, see Fig. 1.

\section{Recruitment}

A total of 60 AS patients age 18-60 years and 30 healthy volunteers will be recruited for this study. AS participants will be recruited from both the outpatient and inpatient departments of the GPHCM, Department of Rheumatology. Study flyers, bulletin boards at the hospital, and online advertisements will also be used for patient recruitment. Healthy volunteers will be recruited from among students of the Guangzhou University of Chinese Medicine. Treatment and measurements will be performed at the GPHCM. Participants will contact the recruitment staff by telephone or WeChat. Recruitment staff will be responsible for the enrollment of participants. If they meet the study criteria, they will be invited to the Department of Acupuncture and Moxibustion, Guangdong Provincial Hospital of Chinese Medicine, to undergo the study. Eligible candidates will be asked to sign an informed consent form before intervention begins.

\section{Inclusion criteria}

Recruitment conditions are as follows: (1) a definite diagnosis of axial AS during a stable disease period; (2) $18-60$ years of age, onset age $<40$ years; (3) currently being treated at a stable dose of medication for $\geq 4$ weeks prior to randomization and have received no biologic therapy within the past 3 months; (4) course of disease $\leq 10$ years; and (5) willingness to sign the informedconsent form. Potential participants who satisfy the inclusion criteria will be sent a more detailed information leaflet for informed consent. They will be contacted few days later to determine whether they are interested in participating, and, if so, an appointment will be made for them to visit the Guangdong Provincial Hospital of Chinese Medicine (GPHCM).

\section{Exclusion criteria}

Potential participants will be excluded for the following reasons: (1) clinically important fracture of the spine; (2) spinal deformity or disability; (3) blood coagulation disorder; (4) presence of viral hepatitis, human immunodeficiency virus (HIV), or other blood infection; (5) pregnancy or lactation; (6) previous history of stroke or transient ischemic attacks; (7) pacemaker or other electrical device implanted; or (8) lack of consent, active pursuit of compensation or with pending litigation.

\section{Dropout criteria}

1) Patients who have severe adverse reactions after acupuncture and cannot successfully complete the course of treatment;

2) The participant was unable to follow the protocol treatment for personal reasons during the course or use other traditional Chinese medicine therapies.

\section{Randomization}

A computer algorithm [30] generated a permuted block randomization sequence that will allocate participants to either the acupuncture or sham control acupuncture group to ensure balanced group sizes and allocation concealment. We will use opaque, sealed envelopes in sequential order to contain allocation information.

\section{Blinding}

As this is a single-blinded trial, patients will not know which treatment approach they will undergo. During the data collection and analysis stages, the clinical researcher, assessor, and statistician will not share study information with each other. Blinding will be assessed after the last treatment using a questionnaire that asks participants if they were in the real treatment group or the sham treatment group. The possible responses are "real treatment group," "sham group," or "do not know."

\section{Intervention}

All practitioners in this trial are licensed TCM acupuncture therapists with at least 5 years' clinical experience, and they will be trained to master the study protocol. The acupuncturist will be asked to administer the sham intervention as they would administer standard manipulation, with the same enthusiasm. All participants will continue to receive standard rheumatological care.

\section{Acupuncture group}

The acupuncture intervention program was designed by a senior acupuncturist. The acupoints will be Shenshu (BL23), Ganshu (BL18), Yanglingquan (GB34), Jizhong (DU6), Jinsuo (DU8), Mingmen (DU4), and Yaoyangguan (DU3). We will use sterile, disposable stainless-steel needles $0.3 \mathrm{~mm}$ in diameter, and 25 or $40 \mathrm{~mm}$ in length, depending on the acupoints. After eliciting the Deqi response, the researcher will apply electro-acupuncture by connecting an acupoint nerve stimulator (HANS- 


\begin{tabular}{|c|c|c|c|c|c|c|c|}
\hline \multirow[b]{3}{*}{ TIME POINT(Week) } & \multicolumn{7}{|c|}{ STUDY PERIOD } \\
\hline & \multirow{2}{*}{$\begin{array}{c}\text { Enrollment } \\
-1\end{array}$} & \multirow{2}{*}{$\begin{array}{c}\text { Allocation } \\
0\end{array}$} & \multicolumn{4}{|c|}{ Post-allocation } & \multirow{2}{*}{$\begin{array}{c}\text { Closeout } \\
24\end{array}$} \\
\hline & & & 1 & 6 & 12 & 24 & \\
\hline \multicolumn{8}{|l|}{ ENROLLMENT: } \\
\hline Eligibility screen & $\mathrm{X}$ & & & & & & \\
\hline Informed consent & $\mathrm{X}$ & & & & & & \\
\hline Baseline assessment & $\mathrm{X}$ & & & & & & \\
\hline Allocation & & $\mathrm{X}$ & & & & & \\
\hline \multicolumn{8}{|l|}{ INTERVENTIONS: } \\
\hline Standard & & & & & & & \\
\hline rheumatological care & & 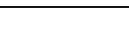 & & & & 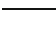 & \\
\hline Acupuncture group & & & & & $\rightarrow$ & & \\
\hline Sham acupuncture & & & & & & & \\
\hline group & & & & & & & \\
\hline Healthy-control & & & & & & & \\
\hline group & & & & & & & \\
\hline ASSESSMENTS: & & & & & & & \\
\hline Musculoskeletal & & & & & & & \\
\hline ultrasound & & & & & & & \\
\hline ASQoL & $\mathrm{X}$ & & & $\mathrm{X}$ & $\mathrm{X}$ & $\mathrm{X}$ & \\
\hline Pain-VAS & $\mathrm{X}$ & & & $\mathrm{X}$ & $\mathrm{X}$ & $\mathrm{X}$ & \\
\hline BASMI & $\mathrm{X}$ & & & $\mathrm{X}$ & $\mathrm{X}$ & $\mathrm{X}$ & \\
\hline$B A S D A I$ & $\mathrm{X}$ & & & $\mathrm{X}$ & $\mathrm{X}$ & $\mathrm{X}$ & \\
\hline BASFI & $\mathrm{X}$ & & & $\mathrm{X}$ & $\mathrm{X}$ & $\mathrm{X}$ & \\
\hline$F S-14$ & $\mathrm{X}$ & & & $\mathrm{X}$ & $\mathrm{X}$ & $\mathrm{X}$ & \\
\hline Adverse events & & & $\mathrm{X}$ & $\mathrm{X}$ & $\mathrm{X}$ & $\mathrm{X}$ & $\mathrm{X}$ \\
\hline
\end{tabular}

Fig. 1 SPIRIT figure for schedule of enrollment, interventions and assessments. ASQoL, Ankylosing Spondylitis Quality of Life; VAS, visual analog scale; BASMI, Bath Ankylosing Spondylitis Metrology Index; BASDAl, Bath Ankylosing Spondylitis Disease Activity Index; BASFl, Bath Ankylosing Spondylitis Functional Index; FS-14, Fatigue Scale-14. 
200A) to Shenshu (BL23) and Ganshu (BL18) at a frequency of $2 \mathrm{~Hz}$ for $30 \mathrm{~min}$. Electro-acupuncture intensity will be set according to the maximum intensity tolerated by each subject $(0.9-3.0 \mathrm{~mA})$. Other needles will be stimulated manually every $10 \mathrm{~min}$. All needles will be left in place for $30 \mathrm{~min}$.

\section{Sham control acupuncture group}

The acupuncture points will be lateral to those in the verum acupuncture group. However, instead of using a 0.25-mm diameter, 25-mm long, sterile disposable stainless-steel needles inserted into acupoints $2-3-\mathrm{mm}$ deep without manipulation and into non-acupoints, we will include NP1 (1 cm outward horizontally of Shenshu [BL23]), NP2 (Ganshu [BL18] level outward by $1 \mathrm{~cm}$ ), NP3 (1 cm behind Yanglingquan [GB34]), NP4 $(1 \mathrm{~cm}$ to the right horizontally of Jizhong [DU6]), NP5 $(1 \mathrm{~cm}$ to the right horizontally of Jinsuo [DU8]), NP6 (1 cm outward horizontally of Mingmen [DU4]), and NP7 (1 cm outward horizontally of Yaoyangguan [DU3]). Next, electroacupuncture will be applied to Shenshu (BL23) and Ganshu (BL18; 0.1-0.3 mA). All needles will be left in place for $30 \mathrm{~min}$. The inclusion of a placebo group will allow for comparison of active acupuncture care effects with manifestations of either sham treatment or psychic solace.

\section{Health control group}

No acupuncture intervention will be conducted in healthy controls.

\section{Outcomes}

\section{Primary outcomes}

Primary outcomes will be musculoskeletal-ultrasound, Ankylosing Spondylitis Quality of Life Scale (ASQoL) results, pain severity, and Bath Ankylosing Spondylitis Metrology Index (BASMI) results. Musculoskeletal ultrasound will use two-dimensional (2D) grayscale, shearwave elastography (SWE) and superb microvascular imaging (SMI) techniques. The 2D grayscale technique will capture muscle thickness changes in the paraspinal and multifidus muscles. Changes in lumbar-muscle thickness can reflect muscle morphological change due to acupuncture treatment for somatic disorders. The lumbar paraspinal muscles play important roles in movement and control of the spine; studies have shown an inverse relationship between lumbar paraspinal-muscle CSA and lower-back disability but not between lumbar paraspinalmuscle CSA and pain intensity, suggesting that treatment strategies directed at increasing paraspinal-muscle size might be effective in reducing lower-back disability [31]. Later, a blinded tester will measure thickness at the levels of the L4-5 zygapophyseal joints using onscreen calipers [32]. SWE is an ultrasound technique that characterizes tissue mechanical properties based on the propagation of remotely induced shear waves [33]. It provides semiquantitative (color map) and quantitative (absolute SWE value) imaging biomarkers that are useful in assessing the elasticity of tendon and muscle composition and stiffness [34, 35] and in helping to distinguish between asymptomatic and symptomatic [36], with diseased tendons being significantly softer than healthy ones [37]. SMI is an ultrasound technique for vascular and microvascular examination. It can diagnose diseases associated with angiogenesis in their early phases and has value in grading disease activities and monitoring therapeutic responses [38]. SMI uses an intelligent algorithm that efficiently separates low-speed flow signals from motion artifacts and successfully extracts clinically relevant information [39]. We will test AS participants using SMI, record resistance index (RI), peak systolic velocity (PSV), and end diastolic velocity (EDV) to reflect SIJ inflammation in this trial. Ultrasound tests will be performed at baseline and week 12 .

The ASQoL, Pain-Visual Analogue Scale for pain (VAS), and BASMI scales have anchors of 0 (none) to 10 (severe). Participants will evaluate their conditions over the preceding week. ASQoL records the impact of AS on health-related QoL from the patient's perspective in terms of sleep, mood, motivation, coping, activities of daily living, independence, relationships, and social life [40]. It is a fixed-response questionnaire that asks endorsement (yes/no) of 18 items, and the total score is the sum of each score. Higher scores reflect low QoL. Regarding reliability, Cronbach's $\alpha$ is reported between 0.89 and 0.92 in the different study groups. Regarding validity, ASQOL correlates moderately well with other AS-specific health outcome measures.

The Pain-VAS is selected to quantitatively evaluate the overall pain level of the body. BASMI [41] is associated with QoL, physical function, and psychological status and reflect the change of lumbar side flexion sensitive and reproducible. It is a composite score based on 5 direct measurements of spinal mobility [42]: lateral lumbar flexion, tragus-to-wall distance, lumbar flexion, intermalleolar distance, and cervical rotation angle, take the mean of the left and right measurements. Add together the scores for each item. Divide this by 5 to give the final BASMI score. The higher the BASMI score, the more severe the patient's limitation of movement due to their AS. BASMI reliability has been shown to be good. Regarding construct validity, the BASMI has been shown to discriminate between patients with and without radiographic change due to AS.

\section{Secondary outcomes}

Secondary outcomes will be Bath Ankylosing Spondylitis Disease Activity Index (BASDAI), Bath Ankylosing Spondylitis Function Index (BASFI), Fatigue Scale-14 (FS-14) results. The BASDAI and BASFI were developed in 1994 using the Visual Analog Scale (VAS) [43, 44]. 
The BASDAI is a patient-generated index measuring disease activity in patients with AS. The index includes 6 items reflect levels of back pain, fatigue, peripheral joint pain and swelling, localized tenderness, and the duration and severity of morning stiffness. Visual analog scale (VAS, $0-10 \mathrm{~cm}$ ) anchored by adjectival descriptors "none" and "very severe," stiffness is anchored by a time scale ( $0-2$ or more hours). The scores for questions 5 and 6 (severity and duration of morning stiffness) are averaged, and the result is then averaged with the remaining 4 question scores to give a final score out of 10. The total scores range from 0 (no disease activity) to 10 (maximal disease activity), and a cut off of 4 is used to define active disease. Internal consistency is good with a Cronbach's $\alpha$ of $0.84-0.87$ [45]. For validity, the BASDAI correlated well with the earlier Bath Disease Activity Index with no significant differences in score distribution, reproducibility, or sensitivity. The BASFI is a patient self-report questionnaire, includes 10 items to measures patients' functional ability in terms of bending, reaching, changing position, standing, turning, and climbing steps. The overall index score is the sum of the individual scores, with higher scores reflecting greater functional impairment. Internal consistency is excellent, with Cronbach's $\alpha$ reported at 0.936 [46]. And have good evidence of validity through comparison with instruments that measure similar or related constructs, and with measures of mobility. The FS-14 measures severity of physical and mental fatigue during their usual daily activities over the past week, which correlates positively with fatigue severity in AS. The FS-14 is a short questionnaire that asks endorsement (yes/no) of 14-item, easy to administer tool, and with good reliability and validity.

\section{Other outcomes}

Participant characteristics of age, weight, body mass index, current medical issues, current medications, and back pain history will be collected using electronic case report forms. Participants will be asked for number and types of medications taken, medication scheduling, and the dose used to self-manage AS symptoms at baseline and at weeks 6 and 12 .

\section{Adverse events}

Common treatment-related adverse events include dizziness, local subcutaneous hematoma, continuous postneedling pain, localized infections, and palpitations. Adverse events data will document the occurrence, duration, and severity of adverse reactions (symptoms and signs), and how the event was resolved (or not) during the treatment. Adverse events will be categorized by acupuncturists and related specialists as treatmentrelated or not within $24 \mathrm{~h}$ after occurrence. If a participant reports a severe adverse event, it should be reported to principal investigators and the Institutional Ethics Committee (IEC) of Guangdong Provincial Hospital of Chinese Medicine, and they will decide to unblind and withdraw from the study. According to the situation, they will be referred to the emergency department or receive appropriate treatment. We will collect, assess, and report any spontaneously described adverse events from participants.

\section{Follow-up}

Follow-up will occur 12 weeks after completion of the treatment program. This time point was selected to assess sustained long-term effectiveness of the intervention.

The trial work plan is summarized in Fig. 2.

\section{Sample size}

The required sample size for this study was estimated based on a study by You et al. [47]: at the week 24, pain VAS score was $3.87 \pm 1.54$ (mean \pm standard deviation [SD]) in needle-knife group and $4.59 \pm 1.57$ in the control group. With a conservative estimate of 0.36point difference on a 10-point VAS score between the two arms, and assuming a standard deviation of 0.72 for both arms, based upon a two sample $t$ tests assuming equal variance analysis conducted by an independent statistician via PASS 15.0, a sample size of 23 per group will yield a power of $90 \%$ at an alpha $(\alpha)$ value of 0.05 . To account for an anticipated dropout rate of $20 \%$, finally, the sample size was inflated to 60 with 30 patients per arm will be sufficient to detect a clinically important difference in this trial.

\section{Data management and monitoring}

The case report form (CRF) includes observation time points, outcome measures, adverse events, and safety evaluations. The outcome assessors will be required to follow the requirements of the CRF and fill in the relevant information in a timely and accurate manner. The data collection and entry will be performed independently by two of the staff members and finalized by a third staff member. The main investigators, acupuncturist, sonographers, and laboratory staff will not be involved in data collection. Data will be obtained from the case record form (CRF), and only members of the trial team have access to the CRFs and perform double-data entry. The paper data will be saved with identification codes in seal. The electronic data will be stored in the ResMan Research Manager. Anonymized trial data will be shared with other researchers at least 3 years after the article is published. If reviewers or readers have any questions regarding our published data, they can contact the corresponding author for access to original data or visit ResMan (http://www. medresman.org/uc/project/projectadd.aspx). We will be 


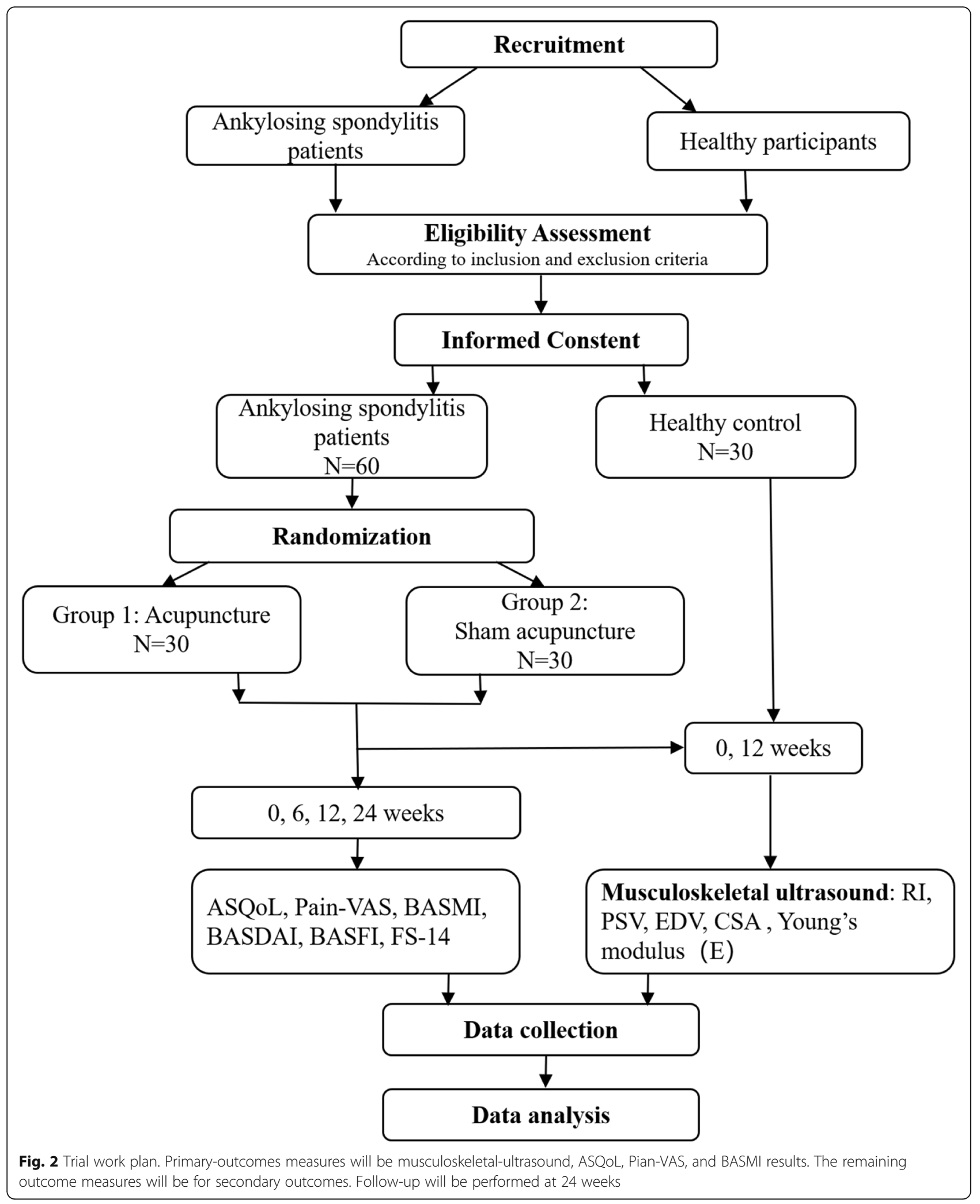


monitored by the IEC of Guangdong Provincial Hospital of Chinese Medicine, and it is independent from the investigators and sponsor which will audit trial conduct every 12 months. And any modifications and corrections to operation procedures will be fully documented using a breach report form, monitored, and submitted to the directors of the ethics committee and China Clinical Trial Registration.

\section{Data analysis}

We will use SPSS software version 18.0 (IBM Corp, Armonk, New York, US) to perform data analysis. Demographic and baseline data will be analyzed with standard descriptive statistics. Data will be presented as the mean \pm standard deviation (SD). Between-group differences will be tested using repeated-measure analyses of variance (ANOVAs). The entire data analysis process will be performed by statisticians who are independent from the research team and blinded to the group settings. The accepted level of significance for all analyses will be $P<0.05$.

\section{Ethics and dissemination}

All candidates who agree to participate and who meet all of the inclusion criteria and none of the exclusion criteria will be provided informed consent to obtain full understanding of what study participation will entail and the potential risks. Participants have the right to discontinue participation at any time. Data will be used in the aggregate only, and no identifying characteristics of individuals will be published or presented. On the consent form, participants will be asked if they agree to use of their data should they choose to withdraw from the trial. Participants will also be asked for permission for the research team to share relevant data with people from the regulatory authorities, where relevant. This trial does not involve collecting biological specimens for storage.

The study conforms to the principles of the Declaration of Helsinki. Ethical approval has been obtained from the IEC of the Guangdong Provincial Hospital of Chinese Medicine (YF2019-232-01). The trial protocol has been registered at the Chinese Clinical Trial Registry (ChiCTR2000031476). Results will be disseminated through journal articles, a master's thesis, or conference presentations. Data will be used in the aggregate only, and no identifying characteristics of individuals will be published or presented.

\section{Discussion}

The purpose of this trial is to assess the impact of acupuncture in the management of AS. It is clear that increased muscle stiffness is associated with poor range of motion [48], and a chronic inflammatory condition has significant impact on QoL. Patients report that back pain, arthralgia, and stiffness influence their daily work productivity and nocturnal sleep quality [49]. Acupuncture is used to reduce muscle stiffness and increase somatic activity in AS patients, and it is monitored by musculoskeletal-ultrasound techniques that, if less operator dependent, could obtain more-stable and reliable results [50]. The design of an appropriate control group for a clinical trial is critical. We will set a healthycontrol group for baseline comparison, as there is currently no standardized for musculoskeletal-ultrasound measurement of AS. However, it is difficult to use placebo needles for controls. Therefore, we will use nonacupoints and superficial puncturing, which are considered ineffective, in the sham acupuncture group.

NSAIDs are often first-line treatment for AS, and biologics are the next step up. However, patients who have inadequate response to NSAIDs but cannot afford biologics often experience significant pain and impairment of their QoL [51]. This trial would provide evidence for acupuncture care for this group of patients.

Despite the measures taken to ensure a well-controlled trial, there are several methodological limitations to this study. The treatment intervention duration of 12 weeks might make it difficult to ensure patient compliance. Other aspects such as the trial results are meant to describe an approach to treatment for the typical patient and cannot anticipate all possibilities; clinicians must make careful clinical assessments based on sound clinical judgment of each patient's circumstances and consideration of the patient's preferences. In spite of its limitations, we hope that the trial will help provide new insights into the value of acupuncture and the evidence of musculoskeletal-ultrasound measures in AS.

\section{Trial status}

This trial is currently recruiting participants. Participants will be recruited for this study started in June 2020 and expected finish in December 2021. The protocol version number is 2019103103, date January 14, 2020.

\footnotetext{
Abbreviations

AS: Ankylosing spondylitis; QoL: Quality of life; SWE: Wave elastography; SMI: Superb microvascular imaging; SIJ: Sacroiliac joint; BASMI: Bath Ankylosing Spondylitis Metrology Index; ASQoL: Ankylosing Spondylitis Quality of Life Scale; BASDAl: Bath Ankylosing Spondylitis Disease Activity Index; BASFI: Bath Ankylosing Spondylitis Function Index; FS-14: Fatigue scale-14; SAS: Self-Rating Anxiety Scale; SDS: Self-rating depression scale; CSA: Cross-sectional area; NSAIDs: Non-steroidal antiinflammatory drugs; TCM: Traditional Chinese Medicine; ACR: American College of Rheumatology; MRI: Magnetic resonance imaging; OMERACT: Outcome Measures in Rheumatology; OMI: Outcome measurement instrument; SpA: Spondyloarthritis; RCT: Randomized controlled trial; CONSORT: Consolidated Standards of Reporting Trials; STRICTA: Standards for Reporting Interventions in Clinical Trials of Acupuncture; GPHC M: Guangdong Provincial Hospital of Chinese Medicine; SPIR IT: Recommendations for Interventional Trials; HIV: Human immunodeficiency virus; 2D: Two-dimensional; Rl: Resistance index; PSV: Peak systolic velocity; EDV: End diastolic velocity; VAS: Visual analog scale; SD: Standard deviation;
} 
ANOVAs: Analyses of variance; CRF: Case report form; IEC: Institutional Ethics Committee

\section{Acknowledgements}

We thank LetPub (www.letpub.com) for its linguistic assistance during the preparation of this manuscript.

\section{Authors' contributions}

ZPL conceived and designed the trial and obtained funding for the trial. MYW and WF drafted the manuscript and performed the trial registration. LCM and JJL performed musculoskeletal ultrasound operation and provided critical revision of the manuscript. LHW designed the statistical analysis. YJP participated in the data collection. The authors have read and approved the final manuscript.

\section{Funding}

This trial is funded by the Studio of Southern China Acupuncture and Herbal Medicine Combination School in the Guangdong Provincial Hospital of Chinese Medicine (No. E43612) (E-mail: Ilbgs@gzucm.edu.cn). The sponsor as well as the funder has not taken part in the study design, data collection and management, analysis, and interpretation of the data; writing of the report; and the decision to publish or the preparation of the manuscript. The funder does not have ultimate authority over any of these activities.

\section{Availability of data and materials}

Not applicable.

\section{Declarations}

\section{Ethics approval and consent to participate}

This study was approved by the Institution Ethics Committee of Guangdong Provincial Hospital of Chinese Medicine (No.YF2019-232-01). Written informed consent is required for participation. Protocol amendments, adverse event reporting, and annual review will be overseen by the Institution Ethics Committee of Guangdong Provincial Hospital of Chinese Medicine.

\section{Consent for publication}

Written informed consent was obtained from the patient(s) for publication of this manuscript and accompanying images. A copy of the written consent is available for review by the editor of this journal.

\section{Competing interests}

The authors have no relevant affiliations or financial involvement with any organization or entity with a financial interest in or financial conflict with the subject matter or materials discussed in the manuscript. This includes employment, consultancies, honoraria, stock ownership or options, expert testimony, grants, or patents received or pending, or royalties.

\section{Author details}

${ }^{1}$ The Second Clinical College of Guangzhou University of Chinese Medicine 111 Dade Rd, Guangzhou 510120, Guangdong Province, China. ${ }^{2}$ The First Affiliated Hospital of Henan University of Chinese Medicine, 19 Renmin Rd, Zhengzhou 450004, Henan Province, China. ${ }^{3}$ The Second Affiliated Hospital of Guangzhou University of Chinese Medicine, 111 Dade Rd, Guangzhou 510120, Guangdong Province, China. ${ }^{4}$ Shenzhen Bao'an Traditional Chinese Medicine Hospital, Guangzhou University of Chinese Medicine, 25 Yu'an 2nd Rd, Shenzhen 518000, Guangdong Province, China.

\section{Received: 13 January 2021 Accepted: 29 May 2021}

Published online: 07 June 2021

\section{References}

1. Taurog JD, Chhabra A, Colbert RA. Ankylosing spondylitis and axial spondyloarthritis. N Engl J Med. 2016;374(26):2563-74. https://doi.org/10.1 056/NEJMra1406182

2. Zhao J, Huang $\mathrm{C}$, Huang $\mathrm{H}$, Pan JK, Zeng LF, Luo MH, et al. Prevalence of ankylosing spondylitis in a Chinese population: a systematic review and meta-analysis. Rheumatol Int. 2020;40(6):859-72. https://doi.org/10.1007/ s00296-020-04537-0.
3. Dougados M, Baeten D. Spondyloarthritis. Lancet. 2011;377(9783):2127-37. https://doi.org/10.1016/S0140-6736(11)60071-8.

4. Ramonda R, Marchesoni A, Carletto A, Bianchi G, Cutolo M, Ferraccioli G, et al. Patient-reported impact of spondyloarthritis on work disability and working life: the ATLANTIS survey. Arthritis Res Ther. 2016;18(1):78. https:// doi.org/10.1186/s13075-016-0977-2

5. Kwan YH, Fong W, How P, Wee H-L, Leung YY, Phang JK, et al. The impact of axial spondyloarthritis on quality of life (QoL): a comparison with the impact of moderate to end-stage chronic kidney disease on QoL. Qual Life Res. 2018;27(9):2321-7. https://doi.org/10.1007/s11136-018-1900-x.

6. Boonen A, Sieper J, van der Heijde D, Dougados M, Bukowski JF, Valluri S, et al. The burden of non-radiographic axial spondyloarthritis. Sem Arthritis Rheum. 2015:44(5):556-62. https://doi.org/10.1016/j.semarthrit.2014.10.009.

7. Ward MM. Quality of life in patients with ankylosing spondylitis. Rheum Dis Clin North Am. 1998:24(4):815-27. https://doi.org/10.1016/S0889857X(05)70043-0.

8. Ward MM, Deodhar A, Gensler LS, Dubreuil M, Yu D, Khan MA, et al. 2019 Update of the American College of Rheumatology/Spondylitis Association of America/spondyloarthritis research and treatment network recommendations for the treatment of ankylosing spondylitis and nonradiographic axial spondyloarthritis. Arthritis Rheumatol. 2019;71(10): 1599-613. https://doi.org/10.1002/art.41042.

9. Kiltz U, Baraliakos X, Braun J. Management of axial spondyloarthritis. Internist (Berl). 2016;57:1060-8.

10. Galloway JB, Mercer LK, Moseley A, Dixon WG, Ustianowski AP, Helbert M et al. Risk of skin and soft tissue infections (including shingles) in patients exposed to anti-tumour necrosis factor therapy: results from the British Society for Rheumatology Biologics Register. Ann Rheum Dis. 2013;72(2): 229-34. https://doi.org/10.1136/annrheumdis-2011-201108.

11. Sieper J, Rudwaleit M, Baraliakos X, et al. The Assessment of Spondyloarthritis International Society (ASAS) handbook: a guide to assess spondyloarthritis. Ann Rheum Dis. 2009;68(Suppl 2):ii1-44.

12. Grazio S, Grubišić F, Brnić V. Rehabilitation of patients with spondyloarthritis: a narrative review. Med Glas (Zenica). 2019;16(2):10.17392/1047-19 [published online ahead of print, 2019 Aug 1].

13. Ning $H$, Wang $Y$, Yuan $Y$, Ning $H$. Nursing and safety of silver needle diathermy treating ankylosing spondylitis. Pak J Pharm Sci. 2015;28(2 Suppl): 725-9.

14. Efthimiou P, Kukar M. Complementary and alternative medicine use in rheumatoid arthritis: proposed mechanism of action and efficacy of commonly used modalities. Rheumatol Int. 2010;30(5):571-86. https://doi. org/10.1007/s00296-009-1206-y.

15. Ernst E, Lee MS. Acupuncture for rheumatic conditions: an overview of systematic reviews. Rheumatology (Oxford). 2010;49(10):1957-61. https://doi. org/10.1093/rheumatology/keq180.

16. Phang JK, Kwan YH, Goh H, Tan VIC, Thumboo J, Østbye T, et al. Complementary and alternative medicine for rheumatic diseases: a systematic review of randomized controlled trials. Complement Ther Med. 2018;37:143-57. https://doi.org/10.1016/j.ctim.2018.03.003.

17. Ledford C. Spine conditions: mechanical and inflammatory low back pain. FP Essent. 2017:461:15-20.

18. Nishishinya Aquino MB, Pereda CA, Muñoz-Ortego J. Efficacy of acupuncture in rheumatic diseases with spine involvement: systematic review. Med Clin (Barc). 2019;153(6):250-5. https://doi.org/10.1016/j.medcli.2019.04.020.

19. Lv ZT, Zhou X, Chen AM. Acupuncture therapy versus disease-modifying antirheumatic drugs for the treatment of ankylosing spondylitis--a metaanalysis. Forsch Komplementmed. 2015;22(6):395-402. https://doi.org/10.11 59/000442733.

20. Boers M, Kirwan JR, Wells G, Beaton D, Gossec L, d'Agostino MA, et al. Developing core outcome measurement sets for clinical trials: OMERAC filter 2.0. J Clin Epidemiol. 2014;67(7):745-53. https://doi.org/10.1016/j. jclinepi.2013.11.013.

21. Mandl P, Naredo E, Wakefield RJ, Conaghan PG, D'Agostino MA, OMERACT Ultrasound Task Force. A systematic literature review analysis of ultrasound joint count and scoring systems to assess synovitis in rheumatoid arthritis according to the OMERACT filter. J Rheumatol. 2011;38(9):2055-62. https:// doi.org/10.3899/jrheum.110424.

22. Ikeda K. Roles of musculoskeletal ultrasonography in the management of rheumatic diseases. Rinsho Byori. 2015;63(5):580-9 Japanese.

23. Siddle HJ, Mandl P, Aletaha D, Vliet Vlieland TP, Backhaus M, Cornell P, et al. The EULAR points to consider for health professionals undertaking 
musculoskeletal ultrasound for rheumatic and musculoskeletal diseases. Ann Rheum Dis. 2018;77(2):311-3. https://doi.org/10.1136/annrheumdis-2016-21 0741.

24. Ohrndorf S, Boer AC, Boeters DM, ten Brinck RM, Burmester GR, Kortekaas $M C$, et al. Do musculoskeletal ultrasound and magnetic resonance imaging identify synovitis and tenosynovitis at the same joints and tendons? A comparative study in early inflammatory arthritis and clinically suspect arthralgia. Arthritis Res Ther. 2019;21(1):59. https://doi.org/10.1186/s13075-01 9-1824-Z.

25. Enache L, Popescu CC, Micu M, Cojocaru A, Suta VC, Suta M, et al. Ankle involvement in rheumatoid arthritis - a comparison of inflammatory signs on musculoskeletal ultrasound and magnetic resonance imaging. Med Ultrason. 2019;21(3):265-72. https://doi.org/10.11152/mu-2038.

26. Delle Sedie A, Riente L, Bombardieri S. Limits and perspectives of ultrasound in the diagnosis and management of rheumatic diseases. Mod Rheumatol. 2008;18(2):125-31. https://doi.org/10.3109/s10165-008-0046-z.

27. Bruyn GA, lagnocco A, Naredo E, Balint PV, Gutierrez M, Hammer HB, et al. OMERACT definitions for ultrasonographic pathologies and elementary lesions of rheumatic disorders 15 years on. J Rheumatol. 2019;46(10):138893. https://doi.org/10.3899/jrheum.181095.

28. Schulz KF, Altman DG, Moher D, CONSORT Group. CONSORT 2010 statement: updated guidelines for reporting parallel group randomised trials. BMJ. 2010;340:c332

29. MacPherson H, Altman DG, Hammerschlag R, Youping L, Taixiang W, White A, et al. Revised STandards for Reporting Interventions in Clinical Trials of Acupuncture (STRICTA): extending the CONSORT statement. J Evid Based Med. 2010;3(3):140-55. https://doi.org/10.1111/j.1756-5391.2010.01086.x.

30. Doig GS, Simpson F. Randomization and allocation concealment: a practical guide for researchers. J Crit Care. 2005;20(2):187-91. https://doi.org/10.1016/ j.jcrc.2005.04.005.

31. Ranger TA, Cicuttini FM, Jensen TS, Heritier S, Urquhart DM. Paraspinal muscle cross-sectional area predicts low back disability but not pain intensity. Spine J. 2019;19(5):862-8. https://doi.org/10.1016/j.spinee.2018.12. 004.

32. Wasser JG, Herman DC, Horodyski MB, Zaremski JL, Tripp B, Page P, et al. Exercise intervention for unilateral amputees with low back pain: study protocol for a randomised, controlled trial. Trials. 2017;18(1):630. https://doi. org/10.1186/s13063-017-2362-0.

33. Eby SF, Song P, Chen S, Chen Q, Greenleaf JF, An KN. Validation of shear wave elastography in skeletal muscle. J Biomech. 2013;46(14):2381-7. https://doi.org/10.1016/j.jbiomech.2013.07.033.

34. Pingel J, Lu Y, Starborg T, Fredberg U, Langberg H, Nedergaard A, et al. 3-D ultrastructure and collagen com-position of healthy and overloaded human tendon: evidence of tenocyte and matrix buckling. J Anat. 2014;224(5):54855. https://doi.org/10.1111/joa.12164.

35. Rosskopf AB, Ehrmann C, Buck FM, et al. Quantitative shear-wave US elastography of the supraspinatus muscle: reliability of the method and relation to tendon integrity and muscle quality. Radiology. 2016;278(2):46574. https://doi.org/10.1148/radiol.2015150908.

36. De Zordo T, Fink C, Feuchtner GM, et al. Real-time sonoelastography findings in healthy Achilles tendons. AJR Am J Roentgenol. 2009;193:134-8.

37. Dirrichs T, Quack V, Gatz M, Tingart M, Kuhl CK, Schrading S. Shear wave elastography (SWE) for the evaluation of patients with tendinopathies. Acad Radiol. 2016;23(10):1204-13. https://doi.org/10.1016/j.acra.2016.05.012.

38. Jiang ZZ, Huang YH, Shen HL, Liu XT. Clinical applications of superb microvascular imaging in the liver, breast, thyroid, skeletal muscle, and carotid plaques. J Ultrasound Med. 2019;38(11):2811-20. https://doi.org/10.1 002/jum.15008.

39. Fu Z, Zhang J, Lu Y, Wang S, Mo X, He Y, et al. Clinical applications of superb microvascular imaging in the superficial tissues and organs: a systematic review. Acad Radiol. 2021;28(5):694-703. https://doi.org/10.1016/ j.acra.2020.03.032

40. Zochling J. Measures of symptoms and disease status in ankylosing spondylitis: Ankylosing Spondylitis Disease Activity Score (ASDAS), Ankylosing Spondylitis Quality of Life Scale (ASQoL), Bath Ankylosing Spondylitis Disease Activity Index (BASDAI), Bath Ankylosing Spondylitis Functional Index (BASFI), Bath Ankylosing Spondylitis Global Score (BAS-G), Bath Ankylosing Spondylitis Metrology Index (BASMI), Dougados Functional Index (DFI), and Health Assessment Questionnaire for the Spondylarthropathies (HAQ-S). Arthritis Care Res (Hoboken). 2011;63(Suppl 11):S47-58.
41. Jenkinson TR, Mallorie PA, Whitelock HC, Kennedy LG, Garrett SL, Calin A. Defining spinal mobility in ankylosing spondylitis (AS). The Bath AS Metrology Index. J Rheumatol. 1994;21(9):1694-8.

42. van der Heijde D, Deodhar A, Inman RD, Braun J, Hsu B, Mack M. Comparison of three methods for calculating the Bath Ankylosing Spondylitis Metrology Index in a randomized placebo-controlled study. Arthritis Care Res (Hoboken). 2012;64(12):1919-22. https://doi.org/10.1002/a cr.21771.

43. Garrett S, Jenkinson T, Kennedy LG, Whitelock H, Gaisford P, Calin A. A new approach to defining disease status in ankylosing spondylitis: the Bath Ankylosing Spondylitis Disease Activity Index. J Rheumatol. 1994;21(12): 2286-91.

44. Calin A, Garrett S, Whitelock H, Kennedy LG, O'Hea J, Mallorie P, et al. A new approach to defining functional ability in ankylosing spondylitis: the development of the Bath Ankylosing Spondylitis Functional Index. Rheumatol. 1994;21(12):2281-5.

45. Haywood KL, M Garratt A, Jordan K, Dziedzic K, Dawes PT. Disease-specific patient-assessed measures of health outcome in ankylosing spondylitis: reliability, validity and responsiveness. Rheumatology (Oxford). 2002:41(11): 1295-302. https://doi.org/10.1093/rheumatology/41.11.1295.

46. Jones SD, Calin A, Steiner A. An update on the Bath Ankylosing Spondylitis Disease Activity and Functional Indices (BASDAI, BASFI): excellent Cronbach's alpha scores. J Rheumatol. 1996;23(2):407.

47. You Y, Cai M, Lin J, Liu L, Chen C, Wang Y, et al. Efficacy of needle-knife combined with etanercept treatment regarding disease activity and hip joint function in ankylosing spondylitis patients with hip joint involvement: a randomized controlled study. Medicine (Baltimore). 2020;99(19):e20019. https://doi.org/10.1097/MD.0000000000020019.

48. Johns RJ, Verna W. Relative importance of various tissues in joint stiffness. J Appl Physiol. 1962;17(5):824-8. https://doi.org/10.1152/jappl.1962.17.5.824.

49. Martindale J, Shukla R, Goodacre J. The impact of ankylosing spondylitis/ axial spondyloarthritis on work productivity. Best Pract Res Clin Rheumatol. 2015;29(3):512-23. https://doi.org/10.1016/j.berh.2015.04.002.

50. Alfuraih AM, O'Connor P, Hensor E, et al. The effect of unit, depth, and probe load on the reliability of muscle shear wave elastography: Variables affecting reliability of SWE. J Clin Ultrasound. 2018;46(2):108-15. https://doi. org/10.1002/jcu.22534.

51. Kwan YH, Fong W, Tan VIC, Lui NL, Malhotra R, Østbye T, et al. A systematic review of quality-of-life domains and items relevant to patients with spondyloarthritis. Semin Arthritis Rheum. 2017;47(2):175-82. https://doi.org/1 0.1016/j.semarthrit.2017.04.002.

\section{Publisher's Note}

Springer Nature remains neutral with regard to jurisdictional claims in published maps and institutional affiliations.

Ready to submit your research? Choose BMC and benefit from:

- fast, convenient online submission

- thorough peer review by experienced researchers in your field

- rapid publication on acceptance

- support for research data, including large and complex data types

- gold Open Access which fosters wider collaboration and increased citations

- maximum visibility for your research: over $100 \mathrm{M}$ website views per year

At BMC, research is always in progress.

Learn more biomedcentral.com/submissions 